\title{
BMJ Open Environmental factors associated with general practitioner consultations for allergic rhinitis in London, England: a retrospective time series analysis
}

Dan Todkill (D) ,,2 Felipe de Jesus Colon Gonzalez, ${ }^{3,4}$ Roger Morbey, ${ }^{5}$ Andre Charlett, ${ }^{6}$ Shakoor Hajat, ${ }^{7}$ Sari Kovats, ${ }^{7}$ Nicholas J Osborne (D) ,,9 Rachel Mclnnes, ${ }^{10}$ Sotiris Vardoulakis, ${ }^{11}$ Karen Exley, ${ }^{12}$ Obaghe Edeghere, ${ }^{1,5}$ Gillian Smith, ${ }^{2,5}$ Alex J Elliot (iD) ${ }^{2,5}$

To cite: Todkill D, de Jesus Colon Gonzalez F, Morbey R, et al. Environmental factors associated with general practitioner consultations for allergic rhinitis in London, England: a retrospective time series analysis. BMJ Open 2020;10:e036724. doi:10.1136/ bmjopen-2019-036724

- Prepublication history for this paper is available online. To view these files, please visit the journal online (http://dx.doi. org/10.1136/bmjopen-2019036724).

Received 16 January 2020 Revised 10 August 2020 Accepted 22 September 2020

Check for updates

(C) Author(s) (or their employer(s)) 2020. Re-use permitted under CC BY-NC. No commercial re-use. See rights and permissions. Published by BMJ.

For numbered affiliations see end of article.

Correspondence to

Dr Dan Todkill;

D.Todkill@warwick.ac.uk

\section{ABSTRACT}

Objectives To identify key predictors of general practitioner (GP) consultations for allergic rhinitis (AR) using meteorological and environmental data.

Design A retrospective, time series analysis of GP consultations for AR.

Setting A large GP surveillance network of GP practices in the London area.

Participants The study population was all persons who presented to general practices in London that report to the Public Health England GP in-hours syndromic surveillance system during the study period (3 April 2012 to 11 August 2014).

Primary measure Consultations for AR (numbers of consultations).

Results During the study period there were 186401 GP consultations for AR. High grass and nettle pollen counts (combined) were associated with the highest increases in consultations (for the category $216-270$ grains $/ \mathrm{m}^{3}$, relative risk (RR) $3.33,95 \% \mathrm{Cl} 2.69$ to 4.12 ) followed by high tree (oak, birch and plane combined) pollen counts (for the category 260-325 grains $/ \mathrm{m}^{3}$, RR $1.69,95 \% \mathrm{Cl} 1.32$ to 2.15) and average daily temperatures between $15^{\circ} \mathrm{C}$ and $20^{\circ} \mathrm{C}(\mathrm{RR} 1.47,95 \% \mathrm{Cl} 1.20$ to 1.81). Higher levels of nitrogen dioxide $\left(\mathrm{NO}_{2}\right)$ appeared to be associated with increased consultations (for the category $70-85 \mu \mathrm{g} / \mathrm{m}^{3}$, RR $1.33,95 \% \mathrm{Cl} 1.03$ to 1.71 ), but a significant effect was not found with ozone. Higher daily rainfall was associated with fewer consultations $(15-20 \mathrm{~mm} /$ day; RR $0.812,95 \% \mathrm{Cl}$ 0.674 to 0.980 ).

Conclusions Changes in grass, nettle or tree pollen counts, temperatures between $15^{\circ} \mathrm{C}$ and $20^{\circ} \mathrm{C}$, and (to a lesser extent) $\mathrm{NO}_{2}$ concentrations were found to be associated with increased consultations for AR. Rainfall has a negative effect. In the context of climate change and continued exposures to environmental air pollution, intelligent use of these data will aid targeting public health messages and plan healthcare demand.

\section{BACKGROUND}

Allergic rhinitis (AR) is a global health problem affecting an estimated 500 million people worldwide. ${ }^{1}$ The symptoms can affect
Strengths and limitations of this study

- This study quantifies the impact of ambient concentrations of individual types of pollen and meteorological factors on general practitioner consultations for allergic rhinitis.

- This study contributes to the small but growing body of evidence quantifying the role of pollen and air pollutants in the burden of allergic rhinitis, controlling for the effects of other environmental and meteorological factors.

- This study demonstrates the potential utility of syndromic surveillance systems in supporting the monitoring of the health impact of pollen exposure.

- The findings should be interpreted in the context of potential exposure measurement errors that are inherent in these types of studies.

- There were insufficient data to include putative predictors (or confounders) such as sulfur dioxide, aggregate $\mathrm{PM}_{10}$, other pollen species and fungal spore measurements in the model.

individuals' sleep, ${ }^{2}$ performance at school ${ }^{3}$ and work, ${ }^{4}$ and AR has substantial financial costs to society; in Sweden, AR has been estimated to cost the economy approximately $€ 2.7$ billion annually. ${ }^{5}$ The prevalence of AR is increasing worldwide, with some countries describing over $50 \%$ of adolescents selfreporting compatible symptoms. ${ }^{6}$ In the UK, prevalence among adults has been estimated at $26 \%(95 \%$ CI $20.3 \%$ to $30.7 \%) .{ }^{7}$ Rhinitis is an inflammation of the lining of the nose characterised by nasal symptoms such as anterior or posterior rhinorrhoea, nasal blockage, sneezing and itching of the nose, and occurring during two or more consecutive days for more than 1 hour on most days. AR is the most common form of non-infectious rhinitis and the symptoms are caused by an IgE-mediated immune response to allergens. 
AR has a multifactorial aetiology that consists of genetic and environmental factors. Some of these triggers have been well described; and include outdoor allergens like pollen grains and moulds, and indoor allergens like mites, animal dander, insects and moulds. ${ }^{1}$

Further to the described association with allergens there is increasing evidence for the association between $\mathrm{AR}$ and three major air pollutants (namely $\mathrm{PM}_{10}$, sulfur dioxide $\left(\mathrm{SO}_{2}\right)$ and nitrogen dioxide $\left.\left(\mathrm{NO}_{2}\right)\right),{ }^{8-10}$ although this relationship has not been consistently demonstrated across all relevant studies. In 2001, Hajat $e t a l^{8}$ investigated the relationship between air pollution and daily general practice consultations for $\mathrm{AR}$ in London using data from 1992 to 1994, and found an association between increasing consultations and ambient concentrations of $\mathrm{SO}_{2}$ and $\mathrm{O}_{3}$, which both contributed independently to the increase.

Despite the growing evidence for the role of air pollutants, the contribution of individual pollen types to consultations for AR has been less well described. Breton et $a l^{11}$ found a significant association between outpatient visits for AR and Ambrosia pollens in Montreal (Quebec, Canada). A Canadian study ${ }^{12}$ found an association between increasing levels of fungal spores or ragweed pollen and increases in paediatric emergency hospital visits for conjunctivitis and AR. They found that an increase of 551 basidiomycetes spores (fungus) $/ \mathrm{m}^{3}$, or of 72 ragweed pollen grains $/ \mathrm{m}^{3}$ was associated with a $10 \%$ increase in visits for conjunctivitis and rhinitis. In Beijing, Zhang $e a^{13}$ found an association between high pollen counts and general practitioner (GP) consultations for $\mathrm{AR}$, however, the authors measured a combined pollen count rather than measuring counts of individual pollen species. Less is known about the relative contribution of individual pollen types to the burden of GP consultations for AR.

In the wider context of a changing climate, continued environmental exposure to air pollution and the socioeconomic burden of AR, greater understanding of the main drivers for this illness is necessary to inform appropriate action at all levels. In this study, we aimed to estimate the contribution of putative meteorological and environmental factors on GP consultations for AR.

\section{METHODS}

\section{Study design}

This was a retrospective, time series analysis of daily GP consultations for AR. The study population was all persons who presented to general practices participating in the Public Health England (PHE) national GP in-hours surveillance system within London over the study period (between 3 April 2012 and 11 August 2014). A case of AR was defined as a GP consultation episode where the GP assigned a Read code (the classification system currently used in the UK practice ${ }^{14}$ ) consistent with AR symptoms (codes included: AR, allergic rhinosinutis and hay fever (5-Byte Read codes H17; Read clinical terms V.3 XE0Y5)) and included in the daily extract used for PHE syndromic surveillance.

\section{Data sources}

\section{GP consultation data}

Within the UK, primary care is led by GPs, communitybased doctors with generalist training. For patients, general practice is normally the first point of medical contact within the healthcare system; GP-led services provide open and unlimited access for patients, dealing with a wide spectrum of health problems. Services are available mainly through scheduled appointments (face to face or via telephone), with urgent unscheduled consultations also available.

The PHE GPIH (General Practitioner In Hours) system has a network of over 3500 GP practices across the UK covering approximately 35 million people (about 53\% of the population) in England ${ }^{15}$ (within London the GPIH system provides coverage in 30 of the 31 administrative districts). ${ }^{16}$ Daily GPIH consultation data are routinely used to monitor the impact of public health events (eg, seasonal influenza) using clinical indicators (eg, influenza-like illness, diarrhoea, vomiting).

For this study, AR consultation data (daily numbers of consultations and denominator GP practice patient populations) were extracted for London for the period 3 April 2012 to 11 August 2014.

\section{Meteorological data}

Daily maximum, minimum and mean temperature $\left({ }^{\circ} \mathrm{C}\right)$, and total precipitation $(\mathrm{mm} /$ day $)$ were taken from a $5 \mathrm{~km}$ gridded datase ${ }^{17}$ provided by the Met Office (the UK's national weather service). The $5 \mathrm{~km}$ grid square containing the London King's College pollen monitoring station was used in this study.

\section{Pollen data}

Daily counts of different pollen species; Betula (birch tree), Quercus (oak tree), Platanus (plane tree), Poaceae (grasses) and Urtica (nettle) measured as grains $/ \mathrm{m}^{3}(\mathrm{~g} /$ $\mathrm{m}^{3}$ ) provided by the Met Office, for the London site of King's College (latitude 51.510732, longitude -0.116938). The three tree pollens peak during a broadly similar time period and were aggregated into one variable, and grass/ nettle pollens were similarly aggregated into one variable for inclusion in the model. The variables were combined as they broadly peaked during similar times and the combination reduced the covariance. Importantly, 'out of season' pollen species levels are considered negligible, and outside of these periods were not collected at the collecting stations and recorded. Periods when data were collected from the London site of King's College (latitude 51.510732, longitude -0.116938 ) measuring station were 03/04/2012-19/08/2012, 14/04/2013-02/09/2013, 01/04/2014-11/08/2014. During 2012, earlier data were available from the pollen collecting station, but not included as GP data in the same format were unavailable. 
Air pollutant data

Daily measurements of $\mathrm{PM}_{2.5}$ (microns), $\mathrm{NO}_{2}$ (ppb), ozone $\left(\mathrm{O}_{3}\right)$ were extracted from the Department for Environment Food \& Rural Affairs. ${ }^{18}$ More than $10 \%$ of data were missing for $\mathrm{SO}_{2}$ and $\mathrm{PM}_{10}$ so were not included. Data were taken from the London North Kensington monitoring station and used as a proxy for London. Less than $10 \%$ of data were missing for $\mathrm{PM}_{2,5}$ values and were filled using scaled data from the Bloomsbury urban background monitoring station (latitude 51.522290, longitude $-0.125889)$, t-tests indicated that there were significant differences between stations and so missing data were imputed using linear regression to model the relationship between pollutant values at different stations. Residual analysis was used to ensure that there were no temporal changes in the relationships between sites.

\section{Data analysis}

Rates and proportion calculations

The expected number of AR cases $E\left(Y_{t}\right)$ at time $t=1, \ldots, T$ was modelled using a distributed lag nonlinear model. ${ }^{1920}$ To account for potential over dispersion in the data, we tested negative binomial and quasi-maximum likelihood Poisson models and selected the model specification with the lowest dispersion parameter. To ensure the robustness of our results, we fitted our models using generalised linear modelling and generalised additive modelling approaches. The general algebraic definition for the negative binomial and Poisson models is given by:

$$
\log (t)=\alpha+t+s+w+b+h+\sum_{i=1}^{2} f\left(x_{t}\right)+\sum_{j=1}^{5} g\left(z_{t}\right)+\sum_{j=1}^{3} k\left(p_{t}\right)
$$

where $\log \left(\mu_{t}\right)$ is a logarithmic link function of the expectation $E\left(Y_{t} \equiv \mu_{t}\right)$, with $Y_{t}$ as the time series of $\mathrm{AR}$ counts. The parameter $\alpha$ denotes the intercept; $t$ corresponds to a linear function of time to account for potential long-term trends in the data. Seasonal trends are modelled using Fourier terms with $4 \mathrm{df} /$ year. Long-term and seasonal trends were controlled for because they may be related to factors other than those considered in this study ${ }^{21}$ and has been used in pollen research previously. ${ }^{22}$ The terms $w, b$ and $h$ denote Boolean variables for the weekends $(w)$, bank holidays (UK public holidays) (b) and school holidays $(h) . f\left(x_{t}\right), g\left(z_{t}\right)$ and $k\left(p_{t}\right)$ indicate the nonlinear and delayed effects of the meteorological, pollen and pollutant predictors, respectively. The relationship between AR and the meteorological, pollen and pollutant predictors is defined in two different ways. The first one corresponds to a 5-day moving average of each predictor time series in the set. The second one consisted of cross-basis functions describing simultaneously the nonlinear form of the relationship between AR and the predictor and its distributed lag effects. ${ }^{19} 20$ Cross-basis functions are implemented here using a distributed-lag nonlinear model which effectively avoids the collinearity issues resulting from the inclusion of a parameter for each lag of the exposure variable; algebraic definitions of the cross-basis functions are described in detail elsewhere. ${ }^{19} 20$

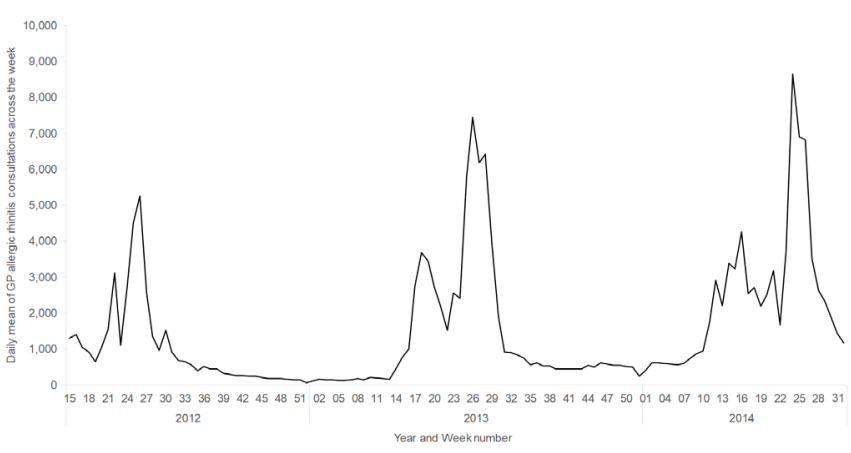

Figure 1 Mean daily number of GP consultations per week, GPIH System, London, 3 April 2012 to 3 August 2014. GP, general practitioner.

\section{RESULTS}

\section{Descriptive epidemiology}

During the study period there were 186401 GP consultations for AR. The mean week-day count of AR consultations was 218 with the range of AR consultations between 0 and 2046. Two distinct seasonal AR peaks were observed: the first peaking during May and the second, larger peak during June (figure 1).

Pollen species were plotted as counts (grains $/ \mathrm{m}^{3}$ ) / day over the study period. Tree pollen species (plane, oak, birch) were more prevalent during the early summer months (AprilMay) while grass and nettle pollen were higher later in the year (July-August). The early AR peak coincided with tree pollens, with the late AR peak at broadly similar time to the grass and nettle pollen (figure 2). The rise in GP consultation rates appeared at broadly similar times to rises in pollen types during each year.

\section{Modelling}

After testing 10 different model specifications, a negative binomial model incorporating daily mean temperature, daily total rainfall, daily aggregated tree pollen, daily aggregated grass and nettle pollen, daily $\mathrm{NO}_{2}$, ozone and $\mathrm{PM}_{2.5}$ were selected. The model explained $\sim 93 \%$ of the deviance in the GP consultations for AR and showed a dispersion parameter close to the unity (1.04), indicating that the negative binomial specification was adequate.

The average estimates of the overall cumulative exposureresponse relationships estimated by the model were plotted

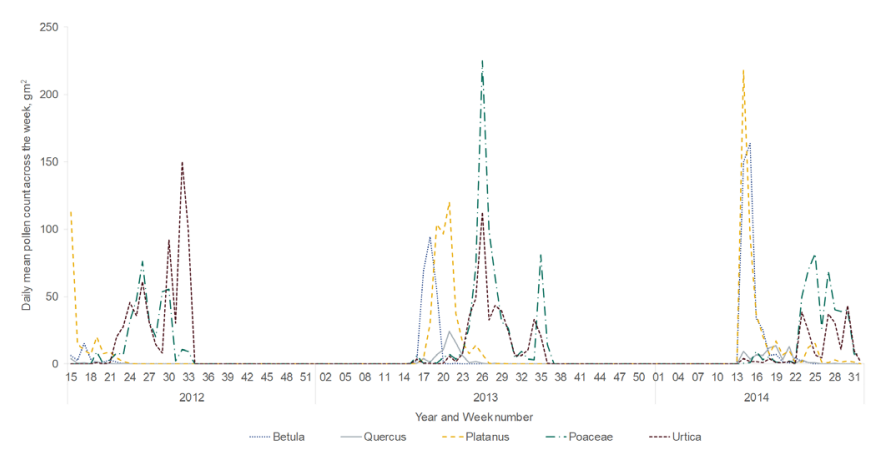

Figure 2 Daily mean pollen counts/week (by species, grains $/ \mathrm{m}^{3}$ ), London, 3 April 2012 to 3 August 2014. 


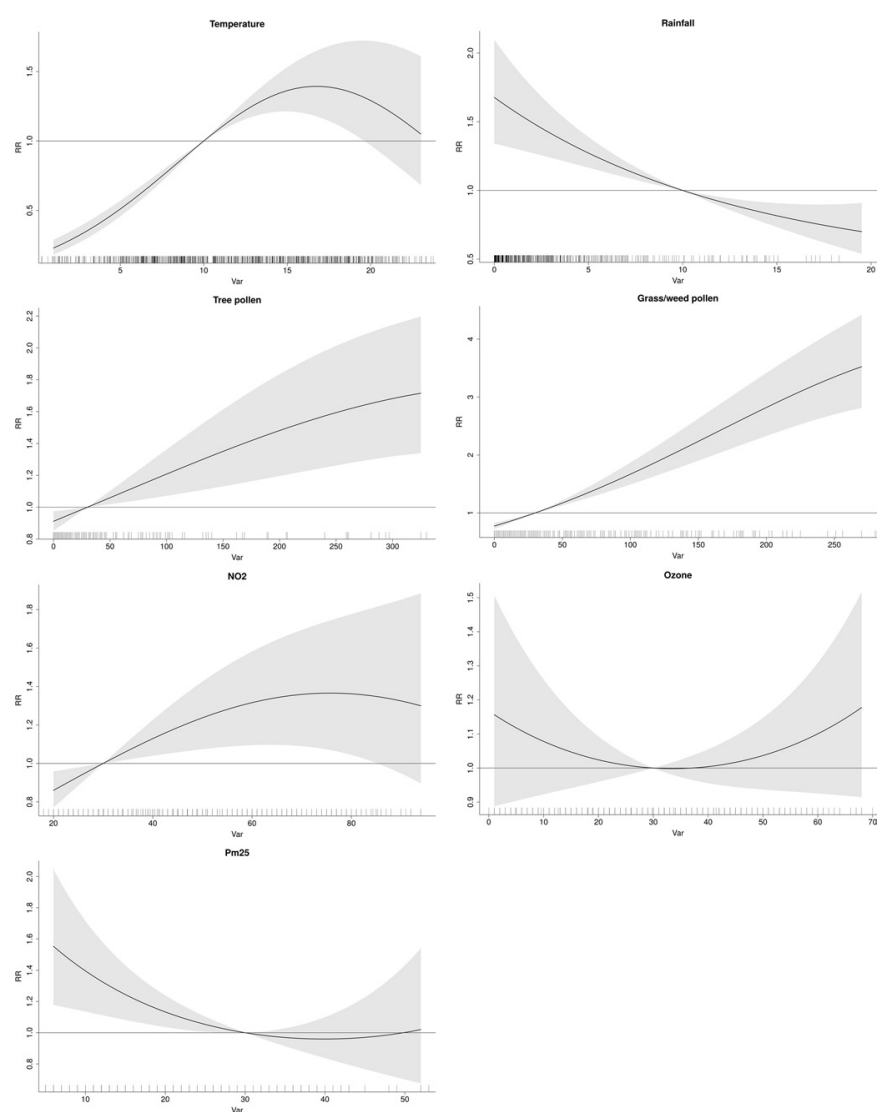

Figure 3 Estimated relationships between allergic rhinitis (AR) GP consultations, temperature, rainfall, aggregated tree and grass/nettle pollen and air pollution from a distributed lag nonlinear model. The $y$ axis (RR or relative risk) represents the excess in AR attendances with respect to the mean values of each covariate. The thick smooth lines indicate the maximum likelihood estimates, and the grey shaded areas represent the 95\% Cls. GP, general practitioner.

(figure 3). The relationships shown were interpreted as the accumulated effect of the predictors on AR over the current and previous 4 days under the assumption that the predictor remained constant over the entire 5-day period.

The results illustrated an overall picture of the delayed effect of temperature on AR compared with a reference value of $10^{\circ} \mathrm{C}$. The relative risk (RR) of an AR consultation gradually increased with increasing temperatures up to approximately $17.5^{\circ} \mathrm{C}$, after which the RR gradually decreased, becoming non-significant at temperatures above $21^{\circ} \mathrm{C}$. The overall mean estimated $\mathrm{RR}$ versus the $10^{\circ} \mathrm{C}$ reference value was 0.55 (95\% CI 0.51 to 0.61 ) for temperatures below $10^{\circ} \mathrm{C}$, and 1.36 (95\% CI 1.13 to 1.66) for temperatures above $10^{\circ} \mathrm{C}$. The estimates of the RR (and their 95\% CIs) of AR were all significant at all levels of temperature except for temperatures between $20^{\circ} \mathrm{C}$ and $25^{\circ} \mathrm{C}$ (table 1 ).

A delayed negative association between rainfall and $\mathrm{AR}$ consultation was found, with the RR decreasing as rainfall increased. The mean RR of AR at values of rainfall below the $10 \mathrm{~mm}$ day threshold was 1.29 (95\% CI 1.16 to 1.45 ) and for values above this threshold the RR was 0.87 (95\% CI 0.78 to 0.97). The effect of rainfall on AR was statistically significant at all levels evaluated in this study (table 1).
Table 1 Daily mean number of AR consultations and RR by metrological, pollen and pollutant variables

\begin{tabular}{|c|c|c|c|}
\hline & $\begin{array}{l}\text { Mean daily } \\
\text { AR consultations }\end{array}$ & RR & $95 \% \mathrm{Cl}$ \\
\hline \multicolumn{4}{|l|}{ Daily temperature } \\
\hline $1.0^{\circ} \mathrm{C}-5.4^{\circ} \mathrm{C}$ & 38 & 0.36 & 0.31 to 0.43 \\
\hline $5.4^{\circ} \mathrm{C}-9.8^{\circ} \mathrm{C}$ & 102 & 0.75 & 0.71 to 0.79 \\
\hline $9.8^{\circ} \mathrm{C}-14.2^{\circ} \mathrm{C}$ & 225 & 1.19 & 1.13 to 1.25 \\
\hline $14.2^{\circ} \mathrm{C}-18.6^{\circ} \mathrm{C}$ & 370 & 1.46 & 1.24 to 1.72 \\
\hline $18.6^{\circ} \mathrm{C}-23.0^{\circ} \mathrm{C}$ & 324 & 1.39 & 0.99 to 1.94 \\
\hline \multicolumn{4}{|l|}{ Daily rainfall } \\
\hline 0-3.9 mm/day & 233 & 1.5 & 1.26 to 1.78 \\
\hline $3.9-7.8 \mathrm{~mm} /$ day & 154 & 1.21 & 1.12 to 1.30 \\
\hline $7.8-11.7 \mathrm{~mm} /$ day & 179 & 1.01 & 1.00 to 1.03 \\
\hline $11.7-15.6 \mathrm{~mm} /$ day & 78 & 0.89 & 0.82 to 0.96 \\
\hline $15.6-19.5 \mathrm{~mm} /$ day & 65 & 0.81 & 0.67 to 0.98 \\
\hline \multicolumn{4}{|l|}{ Tree pollen * } \\
\hline $0-65 \mathrm{~g} / \mathrm{m}^{3}$ & 431 & 1.01 & 0.98 to 1.04 \\
\hline $65-130 \mathrm{~g} / \mathrm{m}^{3}$ & 420 & 1.21 & 1.07 to 1.36 \\
\hline $130-195 \mathrm{~g} / \mathrm{m}^{3}$ & 253 & 1.39 & 1.15 to 1.68 \\
\hline $195-260 \mathrm{~g} / \mathrm{m}^{3}$ & 536 & 1.56 & 1.24 to 1.95 \\
\hline $260-325 \mathrm{~g} / \mathrm{m}^{3}$ & 598 & 1.69 & 1.32 to 2.15 \\
\hline \multicolumn{4}{|l|}{ Grass/Nettle pollen } \\
\hline $0-54 \mathrm{~g} / \mathrm{m}^{3}$ & 309 & 0.97 & 0.94 to 0.99 \\
\hline $54-108 \mathrm{~g} / \mathrm{m}^{3}$ & 605 & 1.47 & 1.35 to 1.60 \\
\hline $108-162 \mathrm{~g} / \mathrm{m}^{3}$ & 359 & 2.08 & 1.79 to 2.41 \\
\hline $162-216 \mathrm{~g} / \mathrm{m}^{3}$ & 541 & 2.73 & 2.27 to 3.29 \\
\hline $216-270 \mathrm{~g} / \mathrm{m}^{3}$ & 517 & 3.33 & 2.69 to 4.12 \\
\hline \multicolumn{4}{|l|}{$\mathrm{NO} 2$} \\
\hline $20-35 \mu \mathrm{g} / \mathrm{m}^{3}$ & 202 & 0.97 & 0.93 to 1.01 \\
\hline $35-50 \mu \mathrm{g} / \mathrm{m}^{3}$ & 263 & 1.12 & 1.02 to 1.23 \\
\hline $50-64 \mu \mathrm{g} / \mathrm{m}^{3}$ & 211 & 1.24 & 1.04 to 1.47 \\
\hline $64-79 \mu \mathrm{g} / \mathrm{m}^{3}$ & 197 & 1.31 & 1.04 to 1.65 \\
\hline $79-94 \mu \mathrm{g} / \mathrm{m}^{3}$ & 141 & 1.33 & 0.98 to 1.82 \\
\hline \multicolumn{4}{|l|}{ Ozone } \\
\hline $1-14 \mu \mathrm{g} / \mathrm{m}^{3}$ & 106 & 1.08 & 0.89 to 1.30 \\
\hline $14-28 \mu \mathrm{g} / \mathrm{m}^{3}$ & 214 & 1.02 & 0.96 to 1.08 \\
\hline $28-41 \mu \mathrm{g} / \mathrm{m}^{3}$ & 290 & 1 & 0.97 to 1.02 \\
\hline $41-55 \mu \mathrm{g} / \mathrm{m}^{3}$ & 230 & 1.01 & 0.92 to 1.11 \\
\hline $55-68 \mu \mathrm{g} / \mathrm{m}^{3}$ & 265 & 1.06 & 0.88 to 1.28 \\
\hline \multicolumn{4}{|l|}{ PM2.5 } \\
\hline $6-15 \mu \mathrm{g} / \mathrm{m}^{3}$ & 230 & 1.41 & 1.15 to 1.73 \\
\hline $15-24 \mu \mathrm{g} / \mathrm{m}^{3}$ & 235 & 1.14 & 1.04 to 1.25 \\
\hline $24-34 \mu \mathrm{g} / \mathrm{m}^{3}$ & 189 & 1.01 & 0.99 to 1.04 \\
\hline $34-43 \mu \mathrm{g} / \mathrm{m}^{3}$ & 132 & 0.98 & 0.88 to 1.09 \\
\hline $43-52 \mu \mathrm{g} / \mathrm{m}^{3}$ & 91 & 1.04 & 0.77 to 1.41 \\
\hline
\end{tabular}

*Aggregated tree pollen grains include Betula (birch tree), Quercus (oak tree) and Platanus (plane tree).

$A R$, allergic rhinitis; $R R$, relative risk.

There was a positive relationship between pollen counts (combined tree, grass and nettle) and AR consultations with the number of GP consultations increasing with increasing 
pollen concentrations. Tree pollen concentrations below 30 grains $/ \mathrm{m}^{3}$ produced an average RR of 0.95 (95\% CI 0.91 to 0.98 ), whereas tree pollen concentrations above the same threshold generated an average RR of 1.41 (95\% CI 1.18 to $1.70)$. Grass/nettle pollen had an average RR of $0.86(95 \%$ CI 0.83 to 0.90 ) at concentrations below $30 \mathrm{~g} / \mathrm{m}^{3}$ and of 2.29 (95\% CI 1.95 to 2.71) at concentrations above that threshold. The effect of concentrations of grass/nettle pollen above 90 grains $/ \mathrm{m}^{3}$ produced a considerable larger effect on AR than that generated by tree pollen (table 1 ).

The magnitude of the associations between AR consultations and air pollution differed depending on the pollutant examined. There was a direct relationship between $\mathrm{NO}_{2}$ and AR consultations with values between 30 and $45 \mathrm{ppb}$ having an RR of 1.08 (95\% CI 1.01 to 1.15 ) rising to an RR of 1.33 (95\% CI 1.03 to 1.71 ), and the RR for $\mathrm{NO}_{2}$ levels below the reference value (30 ppb) having had an average RR of 1.03 (95\% CI 00.93 to 1.16 ).

The effects of $\mathrm{NO}_{2}$ on AR became non-significant at values 85 times above the reference value. The effects of ozone on $\mathrm{AR}$ were non-significant. Finally, the effects of $\mathrm{PM}_{2.5}$ on $\mathrm{AR}$ were significant only at values lower than the 30 times the reference (table 1) with an average RR of 1.23 (95\% CI 1.07 to 1.41$)$.

The model was then re-fitted after disaggregating the two aggregated pollen variables (tree and grass/nettle) into their sub-components (figure 4). The estimated relationships were very similar to those obtained with the aggregated pollen data for most pollens although there were wider CIs around some of the point estimates (eg, Betula); as was expected with a smaller sample size. However, the association between AR consultations and the Oak tree pollen (Quercus) was inverse, a finding that was different to that observed with the other pollen species in the analysis. A closer examination revealed that high concentrations of Quercus pollen always coincided with low concentrations of other tree pollens, which may account for the individual observation.

\section{DISCUSSION}

This study has assessed the relationship between GP consultations for AR and several different variables that are implicated in the overall burden. The observed seasonal pattern of AR consultations is broadly consistent with other studies, ${ }^{14}$ with a large peak occurring in June, preceded by an earlier, smaller peak, usually during April or May. It is apparent from both existing literature and from the results of this study that the fluctuations in AR consultations coincide broadly with pollen peak levels, and that the observed seasonality is predominantly driven by weather and climate drivers, and differences between the flowering times of different types of trees/grasses/weeds ${ }^{23}$ (also known as the 'pollen calendar').

This study has quantified the association between individual pollen species and $\mathrm{AR}$ consultations. The first peak of GP AR consultations was associated with increased tree pollen levels (Platanus, Betula, Quercus), with the second peak of consultations appearing to be associated with increased grass (Poaceae) and nettle (Urtica) levels. These results are
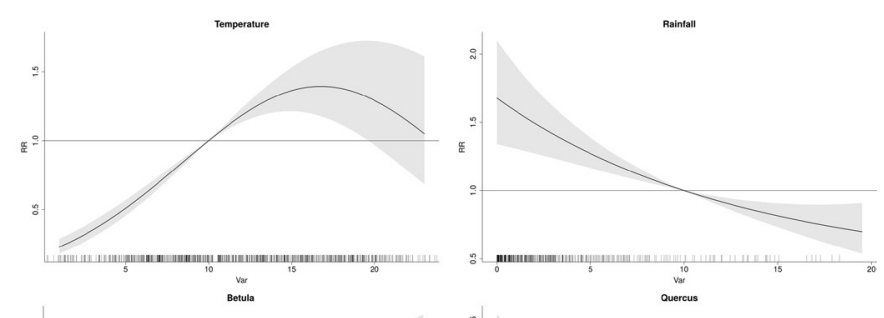

broadly consistent with the known seasonal distribution of pollen, where in general tree pollens are higher during the earlier part of the summer season, with grass/nettle pollens appearing later in the season. ${ }^{23}$ Interestingly, when similar amounts of tree or combined grass and nettle pollens are present, the RR of a GP consultation is higher when exposed to the grass/nettle pollen. The biological reasons for this may include differential effects of some pollens (grasses have been implicated in asthma exacerbations leading to hospitalisations, probably via allergenic asthma hospitalisations). ${ }^{22}$ and there are variations in allergenicity of pollen between trees and grasses. ${ }^{24} \mathrm{~A}$ further finding was in the disaggregated analysis, nettle (Urtica) pollen had a significant effect on GP consultations; these are not usually considered strong allergens, and further work is necessary to better understand this relationship. 
Importantly, the peaks in the AR consultations appeared broadly at similar times to the rises in the observed pollen species. Other studies have described differing lag times between exposure to a putative exposure and occurrence of health effects. Hajat $e t a l^{8}$ identified significant increases in consultations 3 and 4 days following exposure to $\mathrm{SO}_{2}$ and $\mathrm{O}_{3}$, and Breton et al ${ }^{11}$ demonstrated strong correlations between pollen counts and higher medical consultation for AR on days 0-3 and 5 days after elevated pollen exposure, as did Osborne et al. ${ }^{22}$ The spikes in the number of AR consultations appear to precede the rises in the observed pollen species, our findings did not have a lag (day 0). There are several possible reasons for this including the incomplete or delayed capture of pollen at the monitoring sites; and unmeasured variables (which may rise at the same time as the measured variables). Other explanations include potential effectiveness of alerts or media messaging reporting on pollen encouraging patients to seek medical help in advance of symptoms, or weather forecasts/prevailing conditions initiating 'prophylactic' visits to a GP to obtain medication in advance of symptoms. It is likely that these would be recorded with similar diagnostic codes to trigger a consultation being coded as AR in the syndromic surveillance system.

Despite the limitations that this may present in interpreting the results of this study, importantly, from a healthcare systems perspective, this raises the possibility that syndromic surveillance may provide an early warning increasing healthcare activity during periods of rising pollen to the wider healthcare system enabling both timely public health messaging and proactive healthcare planning.

The interpretation of the impact of air pollutants on AR consultations is complex. Pollutants such as carbon monoxide and nitrogen oxide have been reported to contribute to the burden of both AR and asthma. ${ }^{925}$ Our study finds this relationship to be direct and significant for $\mathrm{NO}_{2}$ when accounting for pollen levels, although the impact is clearly less than of the pollen. However, there is an unusual relationship observed between consultations and $\mathrm{PM}_{2.5}$; with a significant effect observed at very low levels, but not replicated at higher loads; the lack of both biological plausibility and dose-response might suggest that finding is an artefact. The lack of effect of ozone has been observed in other studies, ${ }^{26}$ but is complicated by ozone levels often being low in areas where primary emission concentrations are high, and it has been postulated that no (or even a protective) effect from ozone should not be concluded: instead providing further evidence for the impact of other air pollutants. ${ }^{26}$

The observed relationship with temperatures above $20^{\circ} \mathrm{C}$ not being independently associated with increased consultation rates warrants further investigation to understand the reasons behind it. Potentially behavioural factors, where there is a higher propensity for people to be outdoors in warmer temperatures, but as they increase over a certain level move indoors to avoid may have a role, or there could biological factors linked to the release of pollens at different temperatures, such as different species of grass pollen being released at hotter temperatures. ${ }^{27}$

A further interesting finding is that rainfall has an inverse relationship with $A R$ - as rainfall increases $A R$ consultations decreases. The influence of rainfall on pollen concentrations was initially considered to be negative; rainfall washing out airborne pollens from the atmosphere $^{28}$ and has been replicated recently, ${ }^{29}$ however, other studies have found the situation to be more complex ${ }^{30} 31$; and the influence of rainfall in removing pollen from the air is perhaps related to the size of pollen grains for different taxa. ${ }^{32}$ It has been postulated that the absorption of water by pollen grains can lead to them shattering and releasing starch granules, leading to greater exposure with smaller more numerous particles being breathed deeper into the lungs, as in the hypotheses surrounding thunderstorm asthma. Behavioural factors may also be influential; with increasing rainfall people are less likely to spend significant periods of time outside.

There were a number of limitations to this study. First, the results need to be considered with the possibility of measurement bias arising from errors in measuring the exposures. Second, the geographical area used to gather data on GP consultations (upper tier local authority) was much larger than area covered by the few monitoring sites for the environmental exposures; this was a pragmatic approach as only one monitoring site could provide daily pollen count data, but we recognise that the actual individuals' exposure from pollen and air pollutants may have been very localised. Third, GP consultations may be biased towards younger children who are able to obtain free medication, and patients presenting with more severe or persistent symptoms. It is likely that most AR cases in the community will 'self-treat' or 'self-medicate' with antihistamines available without prescription from a pharmacy, and therefore this work may underestimate the overall burden of disease. While this may affect the external validity of our study findings (ie, generalisability to population groups not captured in GP AR data) it is, however, unlikely to affect internal validity. Furthermore, pollen concentration is considered low outside of the usual season and is not measured outside the season, so we were unable to include any out-of-season pollen measurements in our analysis. Finally, there were insufficient data to include either sulfur dioxide, aggregate $\mathrm{PM}_{10}$, other pollen species (in particular Alder and Hazel), and fungal spore measurements in our model; potential independent predictors (and/or confounders) that we were unable to account for in this study, as well as potential synergistic effects of the exposures which we did not explore.

Future work building on the results of this study could incorporate data on other pollen species or fungal spores into the model, and develop forecasting models to provide near real-time predictions of healthcare burden and improve the timeliness of public health messaging during the AR seasons. Recent work by Brennan et $a l^{27}$ 
shows that cutting edge DNA 'barcoding' techniques are now being used to detect individual grass species in the air. Given the greater effect of AR GP consultations found in our study, the possibility to repeat this analysis with counts of individual grass species could lead to new findings about the health impact of specific species of grasses. In the context of climate change and continued exposure to environmental pollutants, intelligent use of these data will be crucial to target public health messaging and plan healthcare demand.

\section{Author affiliations}

${ }^{1}$ Field Epidemiology Training Programme, National Infection Service, Public Health England, Birmingham, UK

${ }^{2}$ Health Services Division, Warwick Medical School, University of Warwick, Coventry, UK

${ }^{3}$ School of Environmental Sciences, University of East Anglia, Norwich, UK

${ }^{4}$ Department of Infectious Disease Epidemiology, London School of Hygiene and

Tropical Medicine, London, UK

${ }^{5}$ Real-time Syndromic Surveillance Team, National Infection Service, Public Health England, Birmingham, UK

${ }^{6}$ Statistics, Modelling and Economics Unit, Public Health England, London, UK ${ }^{7}$ Department of Social and Environmental Health Research, London School of Hygiene and Tropical Medicine, London, UK

${ }^{8}$ School of Public Health, Faculty of Medicine, University of Queensland, Brisbane, Queensland, Australia

${ }^{9}$ European Centre for Environment and Human Health, College of Medicine and Health, University of Exeter, Exeter, UK

${ }^{10}$ Met Office, Exeter, UK

${ }^{11}$ Australian National University, Canberra, Australian Capital Territory, Australia

${ }^{12}$ Air Quality \& Public Health Group, Environmental Hazards and Emergencies Department, Centre for Radiation, Chemical and Environmental Hazards, Public Health England, Chilton, UK

\section{Twitter Nicholas J 0sborne @nosborne36 and Sotiris Vardoulakis @SotirisVard}

Acknowledgements We thank and acknowledge the University of Nottingham, ClinRisk and the contribution of EMIS and EMIS practices; TPP, ResearchOne and the Systm0ne GP practices contributing to this surveillance system. We also thank the PHE Real-time Syndromic Surveillance Team for technical support, in particular Paul Loveridge. We acknowledge the use of Met Office meteorological data, the London North Kensington and Bloomsbury measuring stations (Information provided by the National Meteorological Library and Archive-Met Office, UK). Observational pollen information provided by the National Meteorological Library and ArchiveMet Office, UK. Observed pollen data were collected by London King's College and we thank all the individual collectors at the site for this. We also thank the Met Office who have operated the UK pollen network since 2011.

Collaborators Paul Loveridge.

Contributors DT co-ordinated the project, provided initial analysis and drafted the manuscript. FdJCG completed the statistical analysis. RMo and AC also provided statistical support. SH, SK, NJO, RMc, SV and KE provided expertise in environmental factors. RMc organised data acquisition for environmental variables. OE, GS and AJE provided expertise in Syndromic Surveillance, and organised data acquisition for syndromic data. SK, GS, DT and AJE were involved in the project initiation. All authors contributed to, and commented on the protocol, methodology and final manuscript.

Funding The research was funded through PHE core activities, and supported in part by the National Institute for Health Research Health Protection Research Unit (NIHR HPRU) in Environmental Change and Health (SH, SK, NJO, RMc) at the London School of Hygiene and Tropical Medicine in partnership with PHE, and in collaboration with the University of Exeter, University College London, and the Met Office. FdJCG, RMo, OE, GS and AJE were supported by the NIHR HPRU in Emergency Preparedness and Response at King's College London in partnership with PHE. Funding for open access publication was through the NIHR HPRU in Environmental Change and Health. The views expressed are those of the authors not necessarily those of the NHS, the NIHR, the Department of Health and Social Care or Public Health England.
Competing interests None declared.

Patient and public involvement Patients and/or the public were not involved in the design, or conduct, or reporting, or dissemination plans of this research.

Patient consent for publication Not required.

Provenance and peer review Not commissioned; externally peer reviewed.

Data availability statement Data may be obtained from a third party and are not publicly available. Syndromic surveillance data used in this manuscript originate from the University of Nottingham, ClinRisk EMIS and EMIS practices; TPP, ResearchOne and the Systm0ne GP practices. Metrological and Pollen information was provided by the National Meteorological Library and Archive-Met Office, UK.

Open access This is an open access article distributed in accordance with the Creative Commons Attribution Non Commercial (CC BY-NC 4.0) license, which permits others to distribute, remix, adapt, build upon this work non-commercially, and license their derivative works on different terms, provided the original work is properly cited, appropriate credit is given, any changes made indicated, and the use is non-commercial. See: http://creativecommons.org/licenses/by-nc/4.0/.

\section{ORCID iDs}

Dan Todkill http://orcid.org/0000-0002-4325-4786

Nicholas J 0sborne http://orcid.org/0000-0002-6700-2284

Alex J Elliot http://orcid.org/0000-0002-6414-3065

\section{REFERENCES}

1 Bousquet J, Schünemann HJ, Samolinski B, et al. Allergic rhinitis and its impact on asthma (ARIA): achievements in 10 years and future needs. J Allergy Clin Immunol 2012;130:1049-62.

2 Craig TJ, McCann JL, Gurevich F, et al. The correlation between allergic rhinitis and sleep disturbance. J Allergy Clin Immunol 2004;114:S139-45.

3 Tanner LAJAJMC. Effect of fexofenadine $\mathrm{HCl}$ on quality of life and work, classroom, and daily activity impairment in patients with seasonal allergic rhinitis. Am J Managed Care 1999;5:S235-47.

4 Kessler RC, Almeida DM, Berglund P, et al. Pollen and mold exposure impairs the work performance of employees with allergic rhinitis. Ann Allergy Asthma Immunol 2001;87:289-95.

5 Hellgren J, Cervin A, Nordling S, et al. Allergic rhinitis and the common cold--high cost to society. Allergy 2010;65:776-83.

6 Sears MR, Burrows B, Herbison GP, et al. Atopy in childhood. II. Relationship to airway responsiveness, hay fever and asthma. Clin Exp Allergy 1993;23:949-56.

7 Bauchau V, Durham SR. Prevalence and rate of diagnosis of allergic rhinitis in Europe. Eur Respir J 2004;24:758-64.

8 Hajat S, Haines A, Atkinson RW, et al. Association between air pollution and daily consultations with general practitioners for allergic rhinitis in London, United Kingdom. Am J Epidemiol 2001;153:704-14.

9 Lee YL, Shaw CK, Su HJ, et al. Climate, traffic-related air pollutants and allergic rhinitis prevalence in middle-school children in Taiwan. Eur Respir J 2003;21:964-70.

10 Zhang F, Wang W, Lv J, et al. Time-series studies on air pollution and daily outpatient visits for allergic rhinitis in Beijing, China. Sci Total Environ 2011;409:2486-92.

11 Breton M-C, Garneau M, Fortier I, et al. Relationship between climate, pollen concentrations of Ambrosia and medical consultations for allergic rhinitis in Montreal, 1994-2002. Sci Total Environ 2006;370:39-50.

12 Cakmak S, Dales RE, Burnett RT, et al. Effect of airborne allergens on emergency visits by children for conjunctivitis and rhinitis. Lancet 2002;359:947-8.

13 Zhang F, Krafft T, Zhang D, et al. The association between daily outpatient visits for allergic rhinitis and pollen levels in Beijing. Sci Total Environ 2012;417-418:39-44.

14 Todkill D, Loveridge P, Elliot AJ, et al. Socioeconomic and geographical variation in general practitioner consultations for allergic rhinitis in England, 2003-2014: an observational study. BMJ Open 2017;7:e017038.

15 Public Health England. Real time syndromic surveillance team Website. Real time syndromic surveillance team website, 2019. Available: https://wwwgovuk/government/collections/syndromicsurveillance-systems-and-analysis [Accessed 09 Oct 2019].

16 Harcourt SE, Fletcher J, Loveridge P, et al. Developing a new syndromic surveillance system for the London 2012 Olympic and Paralympic Games. Epidemiol Infect 2012;140:2152-6. 
17 Hollis D, McCarthy M. UKCP09: Met office gridded and regional land surface climate observation datasets. centre for environmental data analysis, 2017.

18 Department for Environment Food \& Rural Affairs, 2019. Available: http://uk-air.defra.gov.uk/ [Accessed 09 Oct 2019].

19 Gasparrini A, Armstrong B, Kenward MG. Distributed lag non-linear models. Stat Med 2010;29:2224-34.

20 Gasparrini A. Distributed lag linear and non-linear models in R: the package dlnm. J Stat Softw 2011;43:1

21 Bhaskaran K, Gasparrini A, Hajat S, et al. Time series regression studies in environmental epidemiology. Int $J$ Epidemiol 2013;42:1187-95.

22 Osborne NJ, Alcock I, Wheeler BW, et al. Pollen exposure and hospitalization due to asthma exacerbations: daily time series in a European City. Int J Biometeorol 2017;61:1837-48.

23 Mclnnes RN. Pollen, allergens, and human health. Oxford research encyclopedia of environmental science, 2019.

24 Jochner S, Lüpke M, Laube J, et al. Seasonal variation of birch and grass pollen loads and allergen release at two sites in the German Alps. Atmos Environ 2015;122:83-93.

25 Guo YL, Lin YC, Sung FC, et al. Climate, traffic-related air pollutants, and asthma prevalence in middle-school children in Taiwan. Environ Health Perspect 1999;107:1001-6.
26 Brunekreef B, Sunyer J. Asthma, rhinitis and air pollution: is traffic to blame? Eur Respir J 2003;21:913-5.

27 Brennan GL, Potter C, de Vere N, et al. Temperate airborne grass pollen defined by spatio-temporal shifts in community composition. Nat Ecol Evol 2019;3:750-4.

28 McDonald MS. Correlation of air-borne grass pollen levels with meteorological data. Grana 1980;19:53-6.

29 Sabit M, Ramos JD, Alejandro GJ, et al. Seasonal distribution of airborne pollen in Manila, Philippines, and the effect of meteorological factors to its daily concentrations. Aerobiologia 2016;32:375-83.

30 Norris-Hill J, Emberlin J. The incidence of increased pollen concentrations during rainfall in the air of London. Aerobiologia 1993;9:27-32.

31 Patel NN, Barnes CS, Dhar M, et al. Association between rainfall and ragweed pollen counts in the Midwest. J Allergy Clin Immunol 2016;137:AB121.

32 Thien F, Beggs PJ, Csutoros D, et al. The Melbourne epidemic thunderstorm asthma event 2016: an investigation of environmental triggers, effect on health services, and patient risk factors. Lancet Planet Health 2018;2:e255-63. 